\title{
Background Noise and Reverberation Times and Acoustical Quality in A University Classrooms in Jeddah, KSA
}

\author{
Summan $A^{*}$ \\ Faculty of Meteorology, Environment and Arid Land Agriculture, King Abdulaziz University, \\ Kingdom of Saudi Arabia \\ Centre of Excellence in Environmental Studies, Kingdom of Saudi Arabia
}

*Corresponding author: Ahmed Summan, Faculty of Meteorology, Environment and Arid Land Agriculture (Environmental Sciences dept.), King Abdulaziz University, Centre of Excellence in Environmental Studies, Jeddah, Kingdom of Saudi Arabia, Email: asumman@kau.edu.sa

\section{Abstract}

This study investigated the acoustical quality of seven classrooms and learning spaces at King Abdulaziz University in Jeddah. The physical characteristics of sounds measured in these classrooms included Background Noise Levels (BNLs - dBA) and Reverberation Times (RTs - seconds). Measurements were conducted in unoccupied conditions. In addition, information about rooms' sizes, design, components and building materials were collected. Results of BNLs and RTs indicated poor acoustical condition in the new classrooms, while old classrooms provided fair or acceptable acoustical quality for learning and teaching based on their RTs. BNLs in the new classrooms ranged from 42 to $71 \mathrm{dBA}$, and RTs ranged from 1 to 1.4 seconds, which all were higher than the allowable BNL ( $35 \mathrm{dBA}$ ) and RT (0.6 seconds) (ANSI 12.60.2010) according to their rooms sizes. This poor acoustical condition were found to be associated with ventilation noise, reflective surfaces, and classroom design. In conclusion, recommendations to improve the acoustical quality for better learning and teaching in the investigated new classrooms were highlighted in this paper.

Keywords: Noise; Time; Verberations; Classroom Design

Abbreviations: BNLs: Background Noise Levels; RTs: Reverberation Times; NIHL: Noise Induced Hearing Loss.

\section{Introduction}

New classrooms and learning paces were built in the new faculty buildings at King Abdulaziz University for male students' campus. A number of instructors were complaining of annoyance and acoustical discomfort during teaching in these new classrooms. From observations it's found that the design of the rooms and building materials used could be some factors behind this problem. Therefore, this investigation was suggested and aimed to evaluate the acoustical quality in these new rooms by selecting a random number of them including new and old, small and large sizes. The investigation carried out the measurement of Background Noise Levels (BNLs) in dBA, and Reverberation
Times (RT) in seconds. These two parameters are substantial to describe the quality of room acoustics that involving classrooms due to their effects on the occupants of learners and instructors as well. In addition, results from this study provided valuable information and guidance to improve the quality of these rooms to be better places for teaching and learning by suggesting suitable/feasible sound control means to decrease high BNLs and RTs.

\section{Literature Review}

Noise is defined as any unwanted or undesirable sound. It is not a new hazard, however, now it is one of the most pervasive occupational hazards. Noise induced hearing loss (NIHL) is one of the most common occupational noise health problems, which is considered the most prevalent irreversible industrial disease [1-3]. During a noisy day/hour 
in workplaces, including schools, workers'/occupants' ears become fatigued. Previous acoustical studies in occupied classrooms, showed that teachers are exposed to high levels of noise, due to the presence of the students, class activities and the excessive background noise from ventilation systems and other sources $[4,5]$.

The evaluation of the acoustical condition in classrooms and its interference with the quality of communication and learning, and the need for high acoustical quality in classrooms, has been discussed in many scientific publications [6-12].

The physical acoustical parameters typically evaluated in classrooms include background noise levels, reverberation times, speech levels/speech intelligibility index, and reduction of sound energy per distance doubling from a source $[4,13-19]$.

Background noise levels, a key measure in most acoustical studies; in unoccupied or empty classrooms, background noise is generated from ventilation or heating systems and other sources from adjacent rooms. Researchers reported high background noise levels ranging from 33 to 55 $\mathrm{dBA}$, which in most cases exceeded the maximum allowable noise level of $35 \mathrm{dBA}$ recommended by ANSI S.12.60 for unoccupied learning rooms or classrooms [20-24]. In occupied classrooms, noise levels are even higher. An average noise level of $55 \mathrm{dBA}$ was reported in occupied classrooms with students who were quiet and $77 \mathrm{dBA}$ when they were working or involved in activities [25].

The second important parameter to be evaluated for classroom acoustics is reverberation time. Reverberation time (RT60) is the time needed, in seconds, for the average sound in a room to decrease by 60 decibels after a source stops generating sound 20 . There are several studies that investigated reverberation time in different unoccupied classrooms. The average of all results of those studies ranged from $1.2 \mathrm{~s}$ to $1.7 \mathrm{~s}[11,19,26-28]$, which are higher than the maximum allowable value of 0.6-0.7 $\mathrm{s}$ for unoccupied classrooms as recommended by ANSI S12.60 and for acceptable speech intelligibility [20].

It is stated that poor acoustical condition in classrooms can negatively affect teachers' health and performance, which in turn can affect the quality of the learning environment for students. Working in noisy environments that require the use of a loud voice to be heard over long periods is also associated with adverse psychological outcomes among teachers, including job-related stress and mental health condition $[29,30]$. Job-related stress was found to be associated with voice problems among teachers [31,32]. As a result, sickness absence, low job satisfaction and retention in the teaching profession are more common among teachers with voice problems or hearing difficulties in the classroom environment [33].

\section{Objectives}

The objective of this research was to evaluate the acoustical quality of a number of university classrooms including new and old classrooms by measuring background noise levels and reverberation times in unoccupied condition.

\section{Materials and Methods}

\section{Site Selection and Description}

A number of four new classrooms (E101, E102, E103, E104) were randomly selected from one faculty building (Environmental Sciences). Each classroom has different size than the other as shown in Table 1. Each of the investigated room was built from reflected walls and floors, acoustics tiles were installed to cover the ceiling of the room. On the contrary, another three old classrooms were investigated from another old faculty building (Computer Sciences). These three classrooms (CL202, C203, C204) were used as classrooms for lecturing and as computer labs. Sizes of each room are also shown in Table 1.

\begin{tabular}{|c|c|c|c|c|c|c|}
\hline \multirow{2}{*}{ Room \# } & \multicolumn{2}{|c|}{ Room size } & \multirow{2}{*}{ Seats \# } & \multicolumn{2}{|c|}{ Construction materials } \\
\cline { 2 - 5 } & Area $\mathbf{~ m}^{\mathbf{2}}$ & Volume, $\mathbf{~ m}^{\mathbf{3}}$ & & Walls & Ceiling & \multicolumn{2}{c|}{ Floor } \\
\hline E101 & 28.21 & 84.63 & $18-20$ & Painted Concrete & Tiles & Marble tiles \\
\hline E102 & 31.72 & 95.16 & $20-22$ & Painted Concrete & Tiles & Marble tiles \\
\hline E103 & 31.72 & 95.16 & $20-22$ & Painted Concrete & Tiles & Marble tiles \\
\hline E104 & 28.48 & 85.44 & $18-20$ & Painted Concrete & Tiles & Marble tiles \\
\hline CL202 & 92.31 & 249.42 & $45-50$ & Painted Concrete & Tiles & Carpet \\
\hline C203 & 31.49 & 85.01 & $20-22$ & Painted Concrete & Tiles & Carpet \\
\hline C204 & 31.7 & 95.1 & $20-22$ & Painted Concrete & Tiles & Vinyl \\
\hline
\end{tabular}

Table 1: Investigated university classrooms sizes and design description and charcteristics. 


\section{Measurement of Background Noise Levels BNLs}

Background noise is comprised of noise from building systems, exterior sound transmission, and sound transmission from adjacent spaces. It is measured in a certain space and time in the absence of any identified sound sources. In a classroom with occupants, excessive background noise can seriously degrade the ability to communicate, decrease concentration, and induce discomfort [20].

BNLs were measured in each classrooms in unoccupied condition and when only ventilation is on. Measurements were conducted by using a fully charged and calibrated integrated sound level meter ISLM (RION NA-29E) with slow response. ISLM was placed at 3 different spots (centre and corners) at a height of $1.5 \mathrm{~m}$ from the ground and about $2-3 \mathrm{~m}$ away from walls in each classroom. The ISLM measured equivalent noise levels "Leq, $\mathrm{dBA}$ " for 1 minute at each spot. All data were recorded on a special sampling sheet.
Averages of the measurements in each were calculated. Final results were then compared with the ANSI (S12.60-2010) acceptability/design criteria for acoustical characteristics in unoccupied learning spaces/classrooms (Table 2).

\section{Measurement of Reverberation Times RTs}

The calculation of RTs (Early Decay Time, EDT, most relevant to verbal communication) was done from impulse responses measured using the WinMLS software, using an 'omnidirectional' (dodecahedral) loudspeaker array as the sound source. This loudspeaker was placed at the centers and in the corners of the unoccupied classrooms with ventilation turned off. The sound level meter [Rion NA-29E] was used as the receiver, and was located at positions in the classroom not near to the walls, or any obstacles. In each unoccupied classroom, the room-average RT was calculated and compared with classroom acceptability/design criteria (Table 2).

\begin{tabular}{|c|c|c|}
\hline Learning Space & Max. BNL dBA & $\begin{array}{c}\text { Maximum RTs (s) - for sound pressure levels } \\
\text { in octave bands with mid-band frequency } \\
\mathbf{5 0 0} \text { to } \mathbf{1 0 0 0} \mathbf{~ H z}\end{array}$ \\
\hline Core learning space with enclosed volume $<283 \mathrm{~m} 3$ & 35 & 0.6 \\
\hline $\begin{array}{c}\text { Core learning space with enclosed volume }>283 \mathrm{~m} 3 \\
\text { and }<566 \mathrm{~m} 3\end{array}$ & 35 & 0.7 \\
\hline $\begin{array}{c}\text { Core learning space with enclosed volume }>566 \mathrm{~m} 3 \\
\text { and all ancillary learning spaces }\end{array}$ & 40 & $\begin{array}{c}\text { Reverberation control for large core learning } \\
\text { spaces C3.3 (ANSI S12.60-2009) }\end{array}$ \\
\hline
\end{tabular}

Table 2: Maximum A-weighted steady background noise levels (BNL) and maximum reverberation times (RTs) in unoccupied, furnished learning spaces (ANSI S12.60-2010).

\section{Results and Discussion}

\section{Rooms Design and Settings}

Through our research literature review and search we couldn't find/access any governing criteria or regulations for University or school buildings, classrooms in Saudi Arabia. There were no identification for typical/standardized designs for classrooms, especially regarding room acoustics. Therefore, our evaluation was relying on our observations and data collection of the existing/actual design and settings of classrooms in universities in Saudi Arabia, and from other available related literature.

The characteristics of the-seven rooms in Table 1 show that they all are of traditional design, which means they are built from regular constructional materials (concrete, bricks, marbles tiles and ceiling tiles). There is no any acoustical treatment; sound absorber materials/panels installed in any of the investigated classrooms especially the new ones. However, the 3 old classrooms in the computer science building (CL202, C203, C204) have carpet and vinyl covering their floors. Moreover, the investigated classrooms are provided with central ventilation systems, and it was found to be low height ventilation and even not controlled acoustically.

Sizes are very similar for the old and new classrooms (ranged from 85 to $95 \mathrm{~m}^{3}$ ) except the computer lab room CL202 that has the largest volume $\left(249 \mathrm{~m}^{3}\right)$ due to the capacity needed. All these summarized factors above can play a role on the acoustical quality of each classroom; background noise levels and reverberation times.

\section{Background Noise Levels BNLs}

Averages of BNLs at each classroom were calculated. These results show that in all 7 have BNL average "Leq" ranged from 39 to $71 \mathrm{dBA}$ classrooms, which are much higher than the maximum acceptable BNL " $35 \mathrm{dBA}$ " for classrooms smaller than $283 \mathrm{~m}^{3}$. These BNLs were measured when "only" ventilation was on in unoccupied furnished classrooms 
(Table 3). However, the new classrooms (E103 and E104) in the Faculty of Environment have louder BNLs "71 and 61
dBA" than BNLs in old classrooms in the Computer sciences building.

\begin{tabular}{|c|c|c|c|c|}
\hline Room \# & BNLs dBA) & (Leq, Average, dBA & Room $\mathbf{m}^{3}$ & $\begin{array}{c}\text { Volume, Max, BNL (ANSI } \\
\text { S.12.60), dBA }\end{array}$ \\
\hline E101 & $41,42,43$ & 42 & 84.63 & \multirow{7}{*}{35} \\
\hline E102 & $41,40,42$ & 41 & 95.16 & \\
\hline E103 & $60,74,71$ & 71 & 95.16 & \\
\hline E104 & $65,53,53$ & 61 & 85.44 & \\
\hline CL202 & $39,40,37$ & 39 & 249.42 & \\
\hline C203 & $45.41,40$ & 43 & 85.01 & \\
\hline C204 & $41,43,43$ & 42 & 95.1 & \\
\hline
\end{tabular}

Table 3: Measured background noise levels (BNL, dBA) in seven university classrooms and their volumes in $\mathrm{m}^{3}$.

These findings of high BNLs meet and are even higher than the findings from similar previous studies [21-24] where BNLs ranged from 35-55 dBA in unoccupied classrooms. There is plenty of evidence from previous research that classroom BNLs that are higher than $35 \mathrm{dBA}$ are detrimental to hearing and understanding speech and thus defect the ability for learning [20]. Apparently, as presented earlier above that design and building factors for the studied classrooms had an effect on the BNLs. The construction/ building materials used in the new classrooms and loud noise of the "low height" ventilation system were the main reasons for these high BNLs. As shown in Table 1 the new classrooms (E101, E102, E103, E104) have low ventilation in height, reflective walls and reflective floors. Earlier studies by Hodgson [4] and Martins, et al. [5] investigated relationship between room design and ventilation loud noise and the acoustical performance, it's found that ventilation with high background noise levels results in exposure to loud occupational noise among school teachers. This was also found to be a cause for teachers to raise their voice during every lecture and might lose their voices. The academic performance of the students in the investigated classrooms can be negatively affected due to their poor acoustical condition and high BNL [33] (Figure 1).

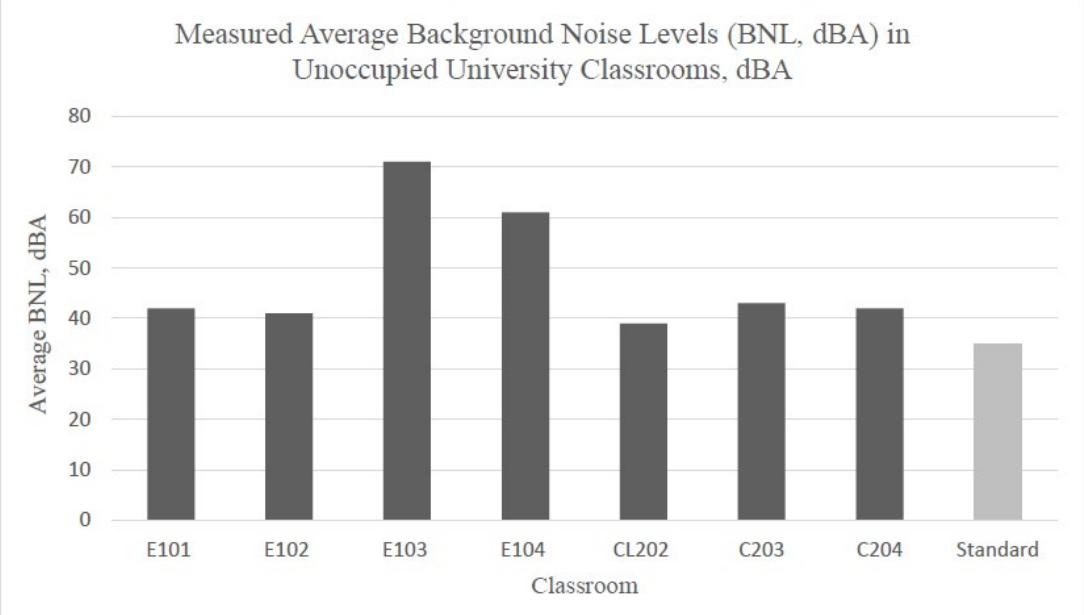

Figure 1: Average Background Noise Levels (dBA) in unoccupied university classrooms.

\section{Reverberation Time, RT:}

Results of measured "averages" RT in the new classrooms ranged from 0.86 and 1.4 seconds in unoccupied condition. These results were found to be exceeding the maximum acceptable RT (0.6 seconds) in unoccupied furnished classrooms at volume $<284 \mathrm{~m}^{3}$ according to ANSI S.12.60. However, in the old classrooms (C203 and C204) 
from the computer sciences faculty, RT were $0.56 \mathrm{~s}$ and 0.58 $\mathrm{s}$ respectively, which are slightly less than the maximum acceptable RT (0.6 seconds) for unoccupied furnished classrooms (Table 4 and Figure 2).

\begin{tabular}{|c|c|c|c|c|}
\hline Room \# & RT (seconds) & Average RT & Room $\mathbf{m}^{3}$ & $\begin{array}{c}\text { Volume, Maximum } \\
\text { (ANSIS.12.60), Seconds }\end{array}$ \\
\hline E101 & $0.8,0.8,1.0$ & 0.86 & 84.63 & \multirow{7}{*}{0.6} \\
\hline E102 & $1.4,1.4,1.4$ & 1.4 & 95.16 & \\
\hline E103 & $1.3,1.5,1.4$ & 1.4 & 95.16 & \\
\hline E104 & $1.0,1.1,0.9$ & 1 & 85.44 & \\
\hline CL202 & $0.62,0.64,0.65$ & 0.63 & 249.42 & \\
\hline C203 & $0.5,0.6,0.6$ & 0.56 & 85.01 & \\
\hline C204 & $0.6,0.6,0.56$ & 0.58 & 95.1 & \\
\hline
\end{tabular}

Table 4: Measured reverberation times (RT, seconds) in seven university classrooms and their volumes in $\mathrm{m}^{3}$.

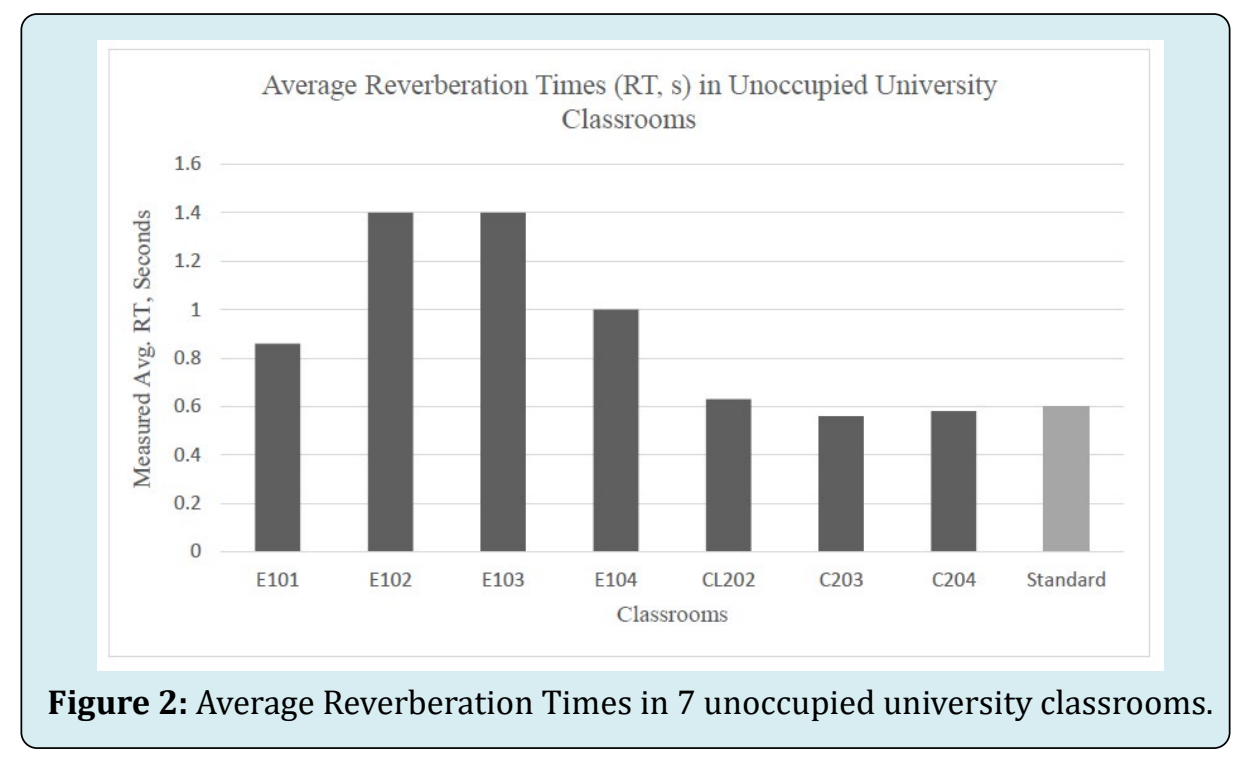

These values of long reverberation times in the new classrooms indicated the poor acoustical condition of room design that doesn't meet the requirement for acceptable classrooms for learning and teaching. Rooms' reflective walls and floors played a role factor in these reverberant learning spaces. In fact, none of these new classrooms is treated acoustically. On the contrary, the old classrooms in the computer sciences faculty have carpeted floors that helped a lot on the reduction of RT and made these rooms acceptable from one point of acoustical quality for learning spaces. These findings met the previous studies that showed measured RT were up to 1.7 in unoccupied classrooms [11,19,26-28]. Reverberant classrooms were investigated in this study can associate with the increment of their background noise levels; the high reflection the surfaces of a room, the longer a sound will continue to bounce around even after the source of the sound has turned off. Therefore, RT can also contribute to the total BNL, where they can reduce the ability to understand speech and raise a risk of noise induced hearing loss among teachers and students.

Moreover, the found results of unacceptable BNLs and RTs in these university classrooms can result in high vocal effort, annoyance, speech interference and distraction [3436].

Teachers who teach and give lectures in these classrooms always tend to raise their voices more than $80 \mathrm{dBA}$ to be heard by their students [37]. Acceptable RTs and BNLs should be achieved to provide better learning spaces for students and teachers in these university classrooms to avoid detrimental effects on the performance and health.

\section{Conclusion}

In general, results of BNLs and RTs of the investigated 
classrooms showed that most of the rooms provide poor acoustical quality. These classrooms didn't have acoustical characteristics that are optimum for learning as recommended by ANSI 12.60.2009 standards for unoccupied classrooms It is clear from this study that classroom acoustics were not considered seriously during the planning stages of construction. Therefore, it is important to recommend and apply a number of modifications on the acoustical characteristics of the studied classrooms. Reduction of RT could be achieved by adding absorbing materials on the walls and /or installing carpet on the floors of the classrooms. Controlling central ventilation system is essential in the reduction of BNL because it is found to be the major source of loud noises in the measured classrooms; this might involve installing sound absorbers and duct silencers around the ducts or change the fan and motor speed.

\section{Declaration of Conflicting Interest}

The Author of this paper declares that there is no conflict of interest.

\section{References}

1. Borchgrevink HM (2003) Does health promotion work in relation to noise? Noise Health 5(18): 25-30.

2. Smith BJ, Peters RJ, Owen S (1996) Acoustics and noise control. Longman.

3. Brink LL, Talbott EO, Burks JA, Palmer CV (2002) Changes over time in audiometric thresholds in a group of automobile stamping and assembly workers with a hearing conservation program. AIHA Journal 63(4): 482487.

4. Hodgson M (2004) Case-study evaluations of the acoustical designs of renovated university classrooms. Applied Acoustics 65(1): 69-89.

5. Martins RH, Tavares EL, Lima Neto AC, Fioravanti MP (2007) Occupational hearing loss in teachers: a probable diagnosis. Rev Bras Otorrinolaringol 73(2): 239-244.

6. Hodgson M (1994) UBC-classroom acoustical survey. Canadian Acoustics 22(4): 3.

7. Berg FS, Blair JC, Benson PV (1996) Classroom acoustics: The problem, impact, and solution. Language, Speech, and Hearing Services in Schools 27(1): 16-20.

8. Dockrell JE, Shield BM (2006) Acoustical barriers in classrooms: The impact of noise on performance in the classroom. British Educational Research Journal 32(3): 509-525.
9. Flexer C (2004) The impact of classroom acoustics: Listening, learning, and literacy. Seminars in hearing 25(2): 131-140.

10. Klatte M, Hellbrück J, Seidel J, Leistner P (2010) Effects of classroom acoustics on performance and well-being in elementary school children: A field study. Environment and Behavior 42(5): 659-692.

11. Picard M, Bradley JS (2001) Revisiting Speech Interference in Classrooms. Audiology 40(5): 221-244.

12. Shield BM, Dockrell JE (2003) The effects of noise on children at school: A review. Building Acoustics 10(2): 97-116.

13. Houtgast TA, Steeneken HJ, Plomp R (1980) Predicting speech intelligibility in rooms from the modulation transfer function. I. General room acoustics. Acta Acustica united with Acustica 46(1): 60-72.

14. Ondet AM, Sueur J (1995) Development and validation of a criterion for assessing the acoustic performance of industrial rooms. The Journal of the Acoustical Society of America 97(3): 1727-1731.

15. Hodgson M, Rempel R, Kennedy S (1999) Measurement and prediction of typical speech and background-noise levels in university classrooms during lectures. The Journal of the Acoustical Society of America 105(1): 226233.

16. Hodgson M, Nosal EM (2002) Effect of noise and occupancy on optimal reverberation times for speech intelligibility in classrooms. The Journal of the Acoustical Society of America 111(2): 931-939.

17. Knecht HA, Nelson PB, Whitelaw GM, Feth LL (2002) Background noise levels and reverberation times in unoccupied classrooms. American Journal of Audiology 11(2): 65-71.

18. Bradley JS (2002) Optimising sound quality for classrooms. In Proceedings of XX Meeting of SOBRAC (Brazilian Acoustical Association), pp: 1-15.

19. Losso M, Viveiros E, Figueiredo T (2004) An overview of acoustical features in Brazilian school buildings. Proceedings of Inter-Noise, Prague, Czech Republic, pp: 1-7.

20. (2010) American National Standards Institute. Acoustical performance criteria, design requirements, and guidelines for schools, part 1: Permanent schools (ANSI S12.60-2010).

21. Celik E, Karabiber Z (2000) A pilot study on the ratio of 
schools and students affected from noise. In Proceedings International symposium on Noise Control and Acoustics for Educational Buildings, Turkish Acoustical Society, Istanbul, pp: 119-128.

22. Bowden E, Wang L, Bradley D (2002) Classroom acoustics in Omaha, Nebraska: Measurements and outreach. The Journal of the Acoustical Society of America 112(5): 2430-2430.

23. Sato H, Bradley JS (2008) Evaluation of acoustical conditions for speech communication in working elementary school classrooms. The Journal of the Acoustical Society of America 123(4): 2064-2077.

24. Shield B, Dockrell JE (2004) External and internal noise surveys of London primary schools. The Journal of the Acoustical Society of America 115(2): 730-738.

25. Airey S (1998) A survey of acoustical standards in UK classrooms and their effect in pupils and teachers. Proceedings of the Institute of Acoustics 20(4): 14-21.

26. Iannace G, Ianniello C, Maffei L, Romano R (2002) Noise problems inside schools in a densely built and temperate climate urban area. International Congress and Exposition on Noise Control Engineering, INTERNOISE.

27. Tachibana H, Ueno K, Aoki A (2002) Study on acoustical conditions in elementary schools of open-plan type in Japan Part 1: Plan features and acoustic properties of schoolrooms. Institute of Noise Control Engineering, INTER-NOISE and NOISE-CON Congress and Conference Proceedings 5: 1141-1146.

28. Nishizawa K, Munakata J, Sakuma T (2004) Survey on acoustic environments for hearing impaired students at schools in Japan. Proceedings 18th Int'l Cong Acoust 2: 921-924.

29. Winkworth AL, Davis PJ (1997) Speech breathing and the Lombard effect. Journal of Speech, Language, and
Hearing Research 40(1): 159-169.

30. Kristiansen J, Lund SP, Persson R, Shibuya H, Nielsen PM, et al. (2014) A study of classroom acoustics and school teachers' noise exposure, voice load and speaking time during teaching, and the effects on vocal and mental fatigue development. International archives of occupational and environmental health 87(8): 851-860.

31. Russell DW, Altmaier E, Van Velzen D (1987) Job-related stress, social support, and burnout among classroom teachers. Journal of applied psychology 72(2): 269-274.

32. Messing K, Seifert AM, Escalona E (1997) The 120s minute: Using analysis of work activity to prevent psychological distress among elementary school teachers. Journal of occupational health psychology 2(1): 45-62.

33. Crandell CC, Smaldino JJ (2000) Classroom acoustics for children with normal hearing and with hearing impairment. Language, speech, and hearing services in schools 31(4): 362-370.

34. Ahlander VL, Rydell R, Lofqvist A (2011) Speaker's comfort in teaching environments: voice problems in Swedish teaching staff. Journal of Voice 25(4):430-440.

35. Pekkarinen E, Viljancn V (1991) Acoustic conditions for speech communication in classrooms. Scandinavian audiology 20(4): 257-263.

36. Pekkarinen E, Himberg L, Pentti J (1992) Prevalence of vocal symptoms among teachers compared with nurses: A questionnaire study. Scandinavian Journal of Logopedics and Phoniatrics 17(2): 113-117.

37. Sala E, Laine A, Simberg S, Pentti J, Suonpaa J (2001) The prevalence of voice disorders among day care center teachers compared with nurses: a questionnaire and clinical study. Journal of Voice 15(3): 413-423. 